\title{
PENERAPAN PENDEKATAN KONSELING RASIONAL EMOTIF TERHADAP PENINGKATAN MOTIVASI BELAJAR SISWA DI MA DDI KAB. PANGKEP
}

\author{
Muhammad Syahrul, Martini \\ Universitas Muslim Indonesia \\ Email: syahruladibaummu@gmail.com,martini@yahoo.com
}

\begin{abstract}
The purpose of this research is to recognize the difference of students' learning motivation in taking mathematics lesson before and after the application of Emotive Rational Counseling. This research includes quantitative research. Sample of the research was 30 students. It was selected by purposive sampling technique. Data was collected by questionnaire. It was then analyzed using descriptive statistical analysis and t-test. The result of this research obtained an experimental subject before taking Emotive Rational counseling of which average value was equal to 61,03. It indicates that the level of student's motivation to participate in math lesson is in low category. After the treatment of Emotive Rational counseling, it obtained an average result of 82.86 . It denotes that the students' motivation level is in high category. From the t-test it obtained the value of $t_{\text {count }}$ of 14.620, while the $t_{\text {table }}$ value at the level of significance is 5 percent with $d_{k}=29$ of 2.045. It states that the research hypothesis was accepted.
\end{abstract}

Keywords: Counseling, Rational Emotive, Learning Motivation

\section{PENDAHULUAN}

Motivasi belajar merupakan kekuatan yang mendorong terjadinya proses belajar. Motivasi belajar pada diri siswa dapat menjadi lemah. Lemahnya motivasi atau tiadanya motivasi belajar akan melemahkan kegiatan belajar (Ahmad Susanto, 2014 :239). Selanjutnya, mutu hasil belajar akan menjadi rendah. Oleh karena itu, motivasi belajar pada diri siswa perlu diperkuat terus-menerus.

Sementara motivasi merupakan syarat mutlak untuk melakukan kegiatan belajar. Hal ini sesuai dengan pendapat Mutabarak (Biolla, 1994: 24) bahwa "terdapat dua faktor yang sangat penting dalam menentukan keberhasilan belajar, yaitu kecerdasan dan motivasi. Dari kedua faktor ini, motivasilah yang terpenting”. Murid yang belajar tanpa motivasi yang tinggi tiada berdaya, murid akan lesu, malas dan cenderung mencari pelarian dari kegiatan belajar. Akan tetapi, semakin ia termotivasi dalam belajar, semakin besar kemungkinan untuk 
mengambil tindakan dalam belajar dalam usahanya mencapai prestasi belajar yang lebih baik. Jadi, motivasi merupakan energi dalam diri seseorang yang menimbulkan minat, gairah dan semangat dalam belajar.

Sementara itu, kenyataan menunjukkan bahwa pemberian motivasi dalam kegiatan belajar oleh guru masih sering terabaikan. Kendatipun dilakukan, hanya sebatas kata-kata pujian dan hadiah yang kurang menggairahkan dan hanya diberikan kepada murid yang berprestasi saja dan bukan kepada murid secara keseluruhan. Akibatnya, murid yang berprestasi tetap berprestasi sedangkan murid yang tidak berprestasi juga tidak akan banyak mengalami perubahan bagi peningkatan prestasinya. Dan pada akhirnya gejolak sosial muncul dalam diri murid khususnya pada murid-murid yang tidak berprestasi seperti rasa jenuh, bosan, acuh tak acuh, kurang bergairah, bahkan kadang kala bersikap kurang ajar dan sebagainya.

Di sekolah ditemukan beberapa siswa yang kurang motivasi belajarnya dalam mengikuti pelajaran, khususnya pada mata pelajaran matematika. Sekolah yang dimaksud adalah Madrasah Aliyah Darul Dakwah Wal Irsyad (MA DDI) Padanglampe Kab.Pangkep,berdasarkan pengamatan yang dilakukan ditemukan beberapa siswa yang hasil prestasi belajarnya rendah terutama pada mata pelajaran matematika, itu sebabkan karena siswa berpikiran irasional berupa perasaan cemas, tidak percaya diri jika sedang belajar matematika dan mereka juga menganggap pelajaran matematika itu sebagai mata pelajaran yang paling sulit. Sehingga siswa ketika belajar matematika tidak ada motivasi untuk mengikuti pelajaran. Siswa yang belajar tanpa ada motivasi maka ia tidak ada semangat atau gairah untuk mengikuti pelajaran tersebut dengan baik, sebagaimana yang dikatakan Djamara (2002: 114) bahwa dalam proses belajar motivasi sangat diperlukan, sebab seseorang yang tidak mempunyai motivasi dalam belajar tidak akan mungkin melakukan aktifitas belajar.

Salah satu cara yang dapat digunakan untuk mengatasi permasalahan tersebut adalah dengan pendekatan Konseling Rasional Emotif. Konseling Rasional Emotif bertujuan mengubah keyakinan yang irasional menjadi rasional 
(Sukardi,1984:89), sehingga siswa yang tadinya motivasi belajarnya rendah karena pemikiran yang irasional dapat termotivasi mengikuti pelajarannya.

Didalam Konseling Rasional Emotif dikenal teori A-B-C-D-E, A adalah keberadaan suatu fakta, suatu peristiwa, dan tingkah laku seseorang. C adalah konsekuensi atau reaksi emosional seseorang, reaksi ini bisa layak dan bisa pula tidak layak. A (peristiwa yang mengaktifkan siswa atau klien) bukan penyebab timbulnya C (Konsekuensi emosional, rendahnya motivasi siswa mengikuti pelajaran matematika). Sementara B (irrasional belief terhadap siswa) yang menjadi penyebab C. Bagaimana gangguan emosional dipertahankan?. Gangguan ini dipertahankan oleh putusan-putusan yang tidak logis yang terus menerus diulang oleh individu, seperti "Aku tidak bersemangat mengikuti pelajaran matematika karena sering merasa cemas, tidak percaya diri dan bahkan menganggap matematika itu sebagai pelajaran yang paling sulit''.Reaksi-reaksi emosional yang terganggu seperti ini, diarahkan dan dipertahankan oleh sistem keyakinan yang meniadakan diri, yang berlandaskan gangguan-gangguan yang irrasional yang telah dimasukkan oleh individu kedalam dirinya.

Setelah A-B-C menyusun disputing (penolakan) terhadap sistem kepercayaan irrasionalnya (irB). Pada dasarnya D adalah penerapan metode ilmiah untuk membantu klien menentang keyakinan-keyakinannya yang tidak rasional yang telah mengakibatkan gangguan-gangguan emosional dan tingkah laku. Sementara Effeck (E) adalah suasana psikologis klien setelah proses Konseling Rasional Emotif berupa teratasinya atau berkurangnya keyakinan-keyakinan irrasional.

Berdasarkan latar belakang masalah makatujuan dari penelitian ini adalah untuk mengetahui perbedaan motivasi belajar siswa dalam mengikuti pelajaran matematika antara sebelum dan sesudah penerapan Konseling Rasional Emotif.

\section{Metode}

Penelitian ini termasuk penelitian kuantitatif.Jumlahsampel penelitian adalah 30 siswa.Sampelpenelitian dipilih dengan teknik purposive sampling yaitu pengambilan sampel dengan mempertimbangkan criteria tertentu dimana kriteria yang dimaksud adalah siswa yang telah diidentifikasi kurang motivasi dalam 
mengikuti pelajaran matematika yang disebabkan karena pemikiran irasional (merasa cemas, tidak percaya diri dalam mengikuti pelajaran matematika dan adanya anggapan bahwa pelajaran matematika itu merupakan pelajaran yang paling sulit). Data dikumpulkan menggunakan angket. Sebelum angket digunakan untuk kegiatan penelitian lapangan, terlebih dahulu dilakukan uji coba angket. Uji coba angket melalui dua tahap. Tahap pertama dengan uji konstruk bimbingan (ahli). Kemudian selanjutnya angket direvisi sesuai dengan masukan dan diuji cobakan pada klien/siswa yang tidak termasuk dalam sampel penelitian. Angket yang telah diuji coba kemudian diolah dan dianalisis dalam menemukan validitas dan realibilitasnya. Rumus yang digunakan untuk analisis validitas setiap item pertanyaan adalah rumus product moment (Arikunto, 2005:72) yaitu sebagai berikut:

$$
\begin{array}{ccc}
R x y= & \frac{N \cdot \Sigma X Y-(\Sigma X)(\Sigma Y)}{\sqrt{[N . \Sigma X}-(\Sigma X)^{2}-\left[N \cdot \Sigma Y(\Sigma Y)^{2}\right]} \\
\text { Rxy } & : & \text { Koefisien korelasi } \\
\Sigma \mathrm{X} & : & \text { Skor butir item dari peubah } \\
\Sigma \mathrm{Y} & : & \text { Skor total daripeubah } \\
\Sigma \mathrm{XY} & : & \text { Hasil kali butir item skor total dari perubah } \\
\mathrm{N} & : & \text { Jumlah responden uji coba }
\end{array}
$$

Uji coba instrumen sebanyak 30 orang responden, dengan kriteria pengujian adalah nilai dari jawaban responden hasil uji lapangan diolah dengan menggunakan pengolahan komputer program SPSS, item angket dinyatakan valid apabila skor nilainya lebih besar atau sama dengan 0.333. sedangkan rumus yang digunakan untuk menguji realibilitas angket penelitian ini adalah rumus Alpha Cronbach (Ihsan, 2002: 17) yaitu: apabila rhitung $>$ rtabel, maka alat ukur tersebut reliable dan juga sebaliknya, jika rhitung $<$ rtabel maka alat ukur tidak reliabel. Dalam penelitian ini, dilakukan uji realibilitas dengan menggunakan SPSS dengan model Alpha Cronbach's yang berdasarkanskala Alpha Cronbach's 0 sampai 1. Data di analisis menggunakan analisis statistik deskriptif dan t-test. 


\section{Hasil}

Tabel: Tingkat motivasi belajar siswa sebelum (pretest) dan sesudah (posttest) pemberian Konseling Rasional Emotif.

\begin{tabular}{|c|c|c|c|c|c|}
\hline \multirow{2}{*}{ Interval } & \multirow{2}{*}{ Kategori } & \multicolumn{2}{|c|}{ Pretest } & \multicolumn{2}{|c|}{ Posttest } \\
\hline & & Frekuensi & Persentase & Frekuensi & Persentase \\
\hline $100,8-120$ & SangatTinggi & 0 & 0 & 0 & 0 \\
\hline $81,6-100,7$ & Tinggi & 0 & 0 & 20 & 66,67 \\
\hline $62,4-81,5$ & AgakRendah & 9 & 30,00 & 7 & 23,33 \\
\hline $43,2-62,3$ & Rendah & 21 & 70,00 & 3 & 10,00 \\
\hline $24-43,1$ & SangatRendah & 0 & 0 & 0 & 0 \\
\hline \multicolumn{2}{|c|}{ Jumlah } & 30 & 100,00 & 30 & 100,00 \\
\hline
\end{tabular}

Sumber :Hasil Angket Penelitian

Berdasarkantabeldiatastampakbahwadari 30 orang responden penelitian pada saat pre test telah diketahui bahwa ada 21 orang atau $70 \%$ yang berada pada kategori motivasi rendah dan ada 9 orang atau $30 \%$ yang berada pada kategori motivasi agak rendah.

Setelah klien atau responden diberikan penerapan Konseling Rasional Emotif, maka diketahui bahwa motivasi belajar siswa di Madrasah Aliyah Darul Dakwah Wal Irsyad (MA DDI) Padanglampe, Kab.Pangkep mengalami peningkatan. Hal ini sesuai dengan hasil post test, bahwa dari 30 orang yang diteliti ternyata ada 20 orang atau $66,67 \%$ responden mengalami peningkatan motivasi belajar dalam mengikuti pelajaran matematika atau berada pada kategori motivasi tinggi, dibanding sebelum perlakuan tidak ada yang berada pada kategori tinggi. Selanjutnya pada kategori agak rendah dan kategori rendah juga ada peningkatan yaitu sebelum perlakuan ada 9 orang berada pada kategori agak rendah dan setelah perlakuan berkurang menjadi 7 orang, sedangkan pada kategori rendah sebelum penerapan ada 21 orangatau $70 \%$ yang berada pada kategori rendah dan setelah perlakuan berkurang menjadi 3 orang atau $10 \%$. 


\section{Uji Hipotesis}

Hipotesis nihil $\left(\mathrm{H}_{0}\right)$ penelitian ini adalah "tidak terdapat perbedaan tingkat motivasi belajar siswa dalam mengikuti pelajaran matematika sebelum dan sesudah diberikan Konseling Rational Emotif di Madrasah Aliyah Darul Dakwah Wal Irsyad (MA DDI) Padanglampe, Kab.Pangkep".

Berdasarkan hasil perhitungan $t$-test diperoleh nilai $t_{\text {hitung }}$ sebesar 14,620 , sedangkan nilai $t_{\text {tabel }}$ pada taraf signifikansi 5 persen dengan $d_{k}=29$ sebesar 2,045, hal itu berarti bahwa nilai $t_{\text {hitung }}$ lebih besar dari $t_{\text {tabel. }}$. Karena nilai $t_{\text {htung }}$ lebih besar daripada $t_{\text {tabel}}$, maka sebagai konsekuensinya adalah hipotesis nihil $\left(\mathrm{H}_{0}\right)$ yaitu "tidak terdapat perbedaan tingkat motivasi belajar siswa sebelum dan sesudah diberikan Konseling Rational Emotifdi Madrasah Aliyah Darul Dakwah Wal Irsyad (MA DDI) Padanglampe, Kab.Pangkep" dinyatakan ditolak, dan sebagai konsekuensinya hipotesis kerja $\left(\mathrm{H}_{1}\right)$ yaitu " terdapat perbedaan tingkat motivasi belajar siswa dalam mengikuti pelajaran matematika sebelum dan sesudah diberikan Konseling Rational Emotifdi Madrasah Aliyah Darul Dakwah Wal Irsyad (MA DDI) Padanglampe, Kab.Pangkep” dinyatakan diterima.

\section{PEMBAHASAN}

Rasional Emotif adalah aliran psikoterapi yang berlandaskan asumsi bahwa manusia dilahirkan dengan potensi, baik untuk berfikir rasional dan jujur maupun untuk berfikir irasional dan jahat. Manusia memiliki kecenderungankecenderungan untuk memelihara diri, berbahagia, berpikir dan mengatakan, mencintai, bergabung dengan orang lain serta tumbuh dan mengaktualkan diri. Akan tetapi, berfikir positif dan rasional, Ellis (Corey, 1998: 240) juga mengungkapkan bahwa:

Manusia memiliki kecenderungan-kecenderungan kearah penghancuran diri, menghindari pikiran, berlambat-lambat, menyesali kesalahankesalahan secara tidak berkesudahan, takhyul, intoleransi, profesinisme dan mencela diri sertamenghindaripertumbuhandanaktulisasidiri.Manusia pun berkenderunganuntukterpakupadapola-polatingkahlaku lama yang disfungsional dan mencari berbagai cara untuk terlibat dalam sabotase diri. 
Proses Konseling Rasional Emotif berusaha agar klien mampu melakukan perubahan secara psikologis, olehnya itu klien perlu diarahkan agar mampu menerima kenyataan bahwa meskipun mereka menciptakan gangguan pada dirinya sendiri, namun klien memiliki kemampuan untuk mengatasi hal tersebut dan memahami masalah kepribadian mereka sendiri, terutama yang berasal dari keyakinan irasionalnya.

Rasional Emotif merupakan suatu bentuk terapi behavioral yang berorientasi pada kognitif, yang seiring dengan kebutuhan masyarakat kemudian berkembang menjadi pendekatan yang tidak menekankan aspek kognitif dan pengolahan emosional, namun juga aspek behavioral sehingga menjadi sebuah terapi yaitu sifatnya relatif, aktif, didaktif, persuasi konfrontatif, dan edukatif.

Motivasi belajar siswa dalam mengikuti pelajaran matematika di Madrasah Aliyah Darul Dakwah Wal Irsyad (MA DDI) Padanglampe, Kab.Pangkep khsusnya kelas dua yang menjadi subjek penelitian ini termasuk rendah. Hal ini diperkuat dengan tingkat motivasi belajar siswa dalam mengikuti pelajaran matematika yang berada pada kategor irendah, sebelum diberikan perlakuan berupa Konseling Rational Emotif.

Hasil penelitian menunjukkan bahwa subyek eksperimen pada saat pretest, secara umum menunjukkan tingkat motivasi belajar siswa dalam mengikuti pelajaran matematika berada dalam kategori rendah. Namun setelah diberikan perlakuan Konseling Rational Emotif berupa latihan mengaktifkan pengalaman, latihan mengenali pemikiran dan keyakinan irasional, latihan mengenali konsekuensi pemikiran dan keyakinan irasional, latihan menghapus keyakinan irasional, latihan mengenali pengaruh negatif, latihan mengenali perasaan baru dan latihan terintegrasi. Hal ini menunjukkan perubahan positif yang signifikan, itu berarti bahwa tingkat motivasi belajar siswa dalam mengikuti pelajaran matematika mengalami peningkatan dari kategori rendah menjadi kategori tinggi atau dari motivasi belajar yang rendah menjadi motivasi belajar yang tinggi.

Berdasarkan hasil analisis statistic deskriptif, diperoleh bahwa pada hakekatnya terdapat perubahan tingkat motivasi belajar pada subjek eksperimen karena telah diberikan perlakuan berupa Konseling Rational Emotif. Hal ini 
dibuktikan dengan pengkajian hipotesis yang menunjukkan adanya perbedaan tingkat motivasi belajar siswa dalam mengikuti pelajaran matematika antara sebelum dan sesudah diberikan Konseling Rational Emotif di Madrasah Aliyah Darul Dakwah Wal Irsyad (MA DDI) Padanglampe, Kab.Pangkep.

\section{PENUTUP}

\section{Kesimpulan}

Kajian dan pembahasan pokok-pokok tentang multikulturalisme dan dihubungkan dengan kondisi negara Indonesia saat ini, kiranya menjadi jelas bahwa multikulturalisme perlu dikembangkan di Indonesia, karena justru dengan kebijakan inilah dapat memaknai dan memahami ke-Bhinnekaan Tunggal Ika, dan keragaman dalam kehidupan masyarakat secara baik, seimbang dan proporsional. Dengan kebijakan ini pula dapat menerapkan persatuan Indonesia dan mengembangkan semangat nasionalisme sebagaimana diharapkan.

Alternatif lain yang banyak dikemukakan untuk mengatasi, paling tidak mengurangi, masalah budaya dan karakter bangsa yang dibicarakan itu adalah pendidikan. Pendidikan dianggap sebagai alternatif yang bersifat preventif karena pendidikan membangun generasi baru bangsa yang lebih baik. Sebagai alternatif yang bersifat preventif, pendidikan diharapkan dapat mengembangkan kualitas generasi muda bangsa dalam berbagai aspek yang dapat memperkecil dan mengurangi penyebab berbagai masalah budaya dan karakter bangsa. Memang diakui bahwa hasil dari pendidikan akan terlihat dampaknya dalam waktu yang tidak segera, tetapi memiliki daya tahan dan dampak yang kuat di masyarakat.

\section{DAFTAR PUSTAKA}

Abdulkarim Soroush, Reason, Freedom \& Democracy in Islam, (Paris, UNESCO, 2000). Hal. 56.

Abineno. 1990. Pokok-Pokok Penting Dari Iman Kristen. BPK Gunung Mulia. Jakarta

Agama. Ciscore Indonesia. Surakarta. 
al-Munawwar, Said Aqil Husin, Aktualisasi Nilai-Nilai Qur'ani dalam Sistem Pendidikan Islam, (Jakarta: Ciputat Press, 2003), Get. I.

Amir, Muhammad, Konsep Masyarakat Islam, (Jakarta, Fikanati, Aneska, 2004). Amitabha Buddha dan Nirvana. Surabaya dan Lawang: Bodhimanda Rumah Suci

Anggawati, Lanny dkk. Kitab Suci Udayana " Khotbah - Khotbah Inspirasi Buddha. Yogyakarta: Vidyasena Yasasan Mendut Indonesia Vihara Vidyaloka,1995 Andre Moller, Ramadan di \}awa; Pandangan dari Luar, (Jakarta; Nalar, 2005), hal. 72.

Azizah, Nuraini. 2010. Multikulturalisme. http://technurlogy.wordpress.com /2010/03/31/multikulturalisme. Akses 3 - 07- 2012

Azra, Azyumardi. Pendidikan Multikultural: Membangun Kembali Indonesia Bhineka Tunggal Ika. Makalah Disampaikan dalam Symposium Internasional Antropologi Indonesia ke-3. Denpasar: Kajian Budaya UNUD, 2002.

Bambang, Noorsena, Religi dan Religiositas Bung Karno, (Denpasar; Yayasan Bali Jagadhita Press, 2000).

Benno Ola T.Pr, Pemetaan Iman Kristiani dalam Muitikuitural, Jurnal LPKUB Perwakilan Medan, edisi I tahun 2005. Hal. 45

Bertens, K., Ekumenisme dan Multikulturalisme, Suara Pembaruan Daily, edisi Minggu, 16 - Mar - '08

Bhagavadgita I Wayan Maswinara, 2005, 36-40

Bhagawata Purana. Oleh Bibe k Debroy dan Dipawali Debroy. Blog Nak Belog = The Truth Is Inside You. Posted : 12 November 2008. www.speqlen.co.id.

Budiyono H.D. 1973. Membina Kerukunan Hidup Antar Umat Beragama. Kanisius. Yogyakarta

Depag RI, Terjemahan Kitab Upanisad, (Jakarta; Balai Pustaka, 2005), Hal. 478 Dirjen Bimbingan Masyarakat Hindu dan Buddha, Sang Hyang Adi Kamahayanikan.

---------, dan IRD, Majalah: Inovasi Kurikulum: Kurikulum Berbasis Mitltikulturalism, Edisi IV, Tahun 2003, hal. 26

Fachruddin, "Ajaran Emanasi Adhi Buddha Dalam Buddha Mahayana", Skripsi 
Fakultas Ushuluddin Institut Agam Islam Negeri Walisongo Semarang,

Freire, Paulo. (2007). Politik Pendidikan: Kebudayaan, Kekuasaan, dan Pembebasan

Hardiman, F. Budi, Belajar dari Politik Multikulturalisme, Pengantar pada buku Kewargaan Multikultural (Jakarta; Pustaka LP3ES Indonesia, 2003).

Hunt, L. dan Walker. Ethnic Dynamics : Petterns of Intergroup Relation in Various Societies. (dalam Tesis Hartoyo. 1996. Keserasian Hubungan Antar Etnik, Faktor Pendorong dan Pengelolaannya. Universitas Indonesia. Jakarta)

IKA UIN Syarif Hidayatullah, Majalah Tsaqafah: Mengagas Pendidikan Multikultural, Vol. I No:2, 2003, hal. 43-44.

John Maruli Situmorang, Inkarnasi-Inkulturasi; Pergulatan Kristus dan Budaya, (Bandung; St. Louis Press, 1998), hal. 46.

K Bertens, Ekumenisme dan MultikulturaHsme, Suara Pembaruan Daily, edisi Minggu, 16 - Mar - '08.

M. Chandra Bosse, Pola Pengembangan Kerukunan Berwawasan Multikultural dalam Pandangan Agama Hindu, SPEQLEN = Blog Nak Belog - The Truth Is Inside You. Posted : 12 November 2008.

Ma'Arif, Jamuin. Manual Advokasi: Resolusi Konflik Antar - Etnik dan Agama. 